\title{
Putting Nairobi's Slums on the Map
}

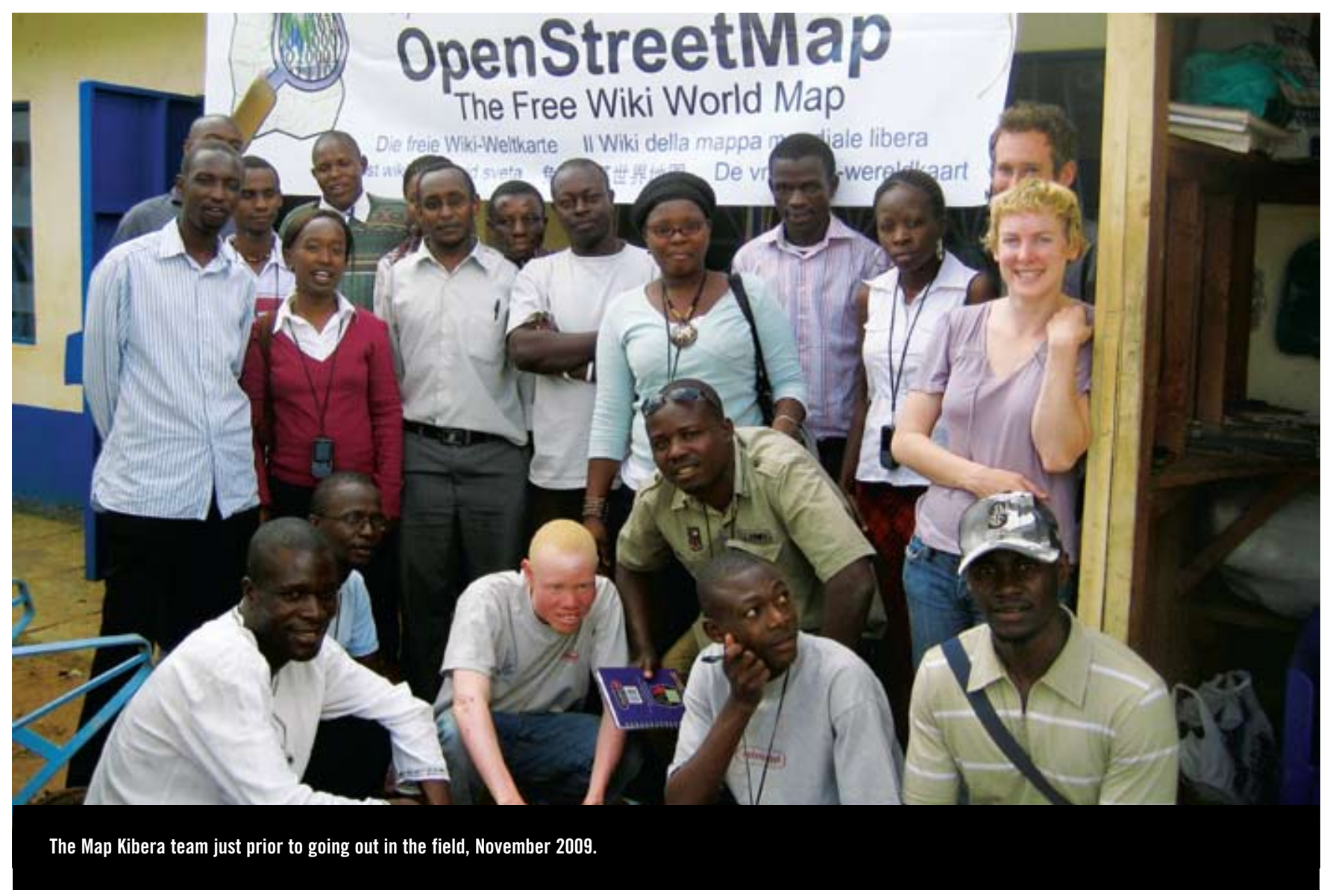

\section{BY ERICA HAGEN}

THE STREETS OF KIBERA, one of the largest slums in Africa, are narrowly winding pathways strewn with garbage, divided down the middle by streams of sewage and waste that make walking treacherous. Corrugated iron and mud shanties are packed together on every possible inch of space. The railroad track provides the only boulevard; its dismantling from time to time serves to vent local frustrations otherwise disregarded by politicians. Electricity is stolen from main power lines or absent entirely. Chickens cluck down the paths, and dogs and goats pick through enormous garbage piles alongside young children.

Kibera, in Nairobi, Kenya, is spread across about $55^{\circ}$ acres of government-owned land, 5 kilometers southwest of the city center. Its population has been calculated at anywhere from 200,000 to more than one million, and varies seasonally. ${ }^{1}$ Historically, the land was given to members of the Nubian
- tribe during the colonial era in exchange for their service in the British Army, but Kibera's land tenure remains informal and is often subject to dispute.

Kibera is nonetheless a vibrant community surviving and often thriving with hundreds of small shops, health clinics, schools, churches, mosques, community groups, movie theaters, corn mills, battery charging kiosks, kerosene stations, water vending points, and pay-showers and latrines. Music pours from radios and CD shops, and life proceeds in a rhythm much like any other urban spot in the world. Until recently, however, the area appeared on public maps only as an amorphous, blank spot labeled "Kibera." In official registers it is designated a forest.

Publicly available information about Kibera is minimal, although it is one of the most heavily studied informal settlements in the world. UN-HABITAT, the United Nations agency for human settlements, is headquartered minutes away, and 
academic and non-governmental organizations frequently survey residents, but the information rarely comes back to the community. Major media outlets do not report on the informal area unless serious violence or turmoil erupts, when they often serve to inflame tensions. Maps that have been made are ever before, determines who enters the conversation about policy-making and access to resources.

With initial funding from Jumpstart International, an American organization, and assistance from Kenyan partners, we began to train a group of thirteen young people between the

\section{KIBERA STRUCTURES}

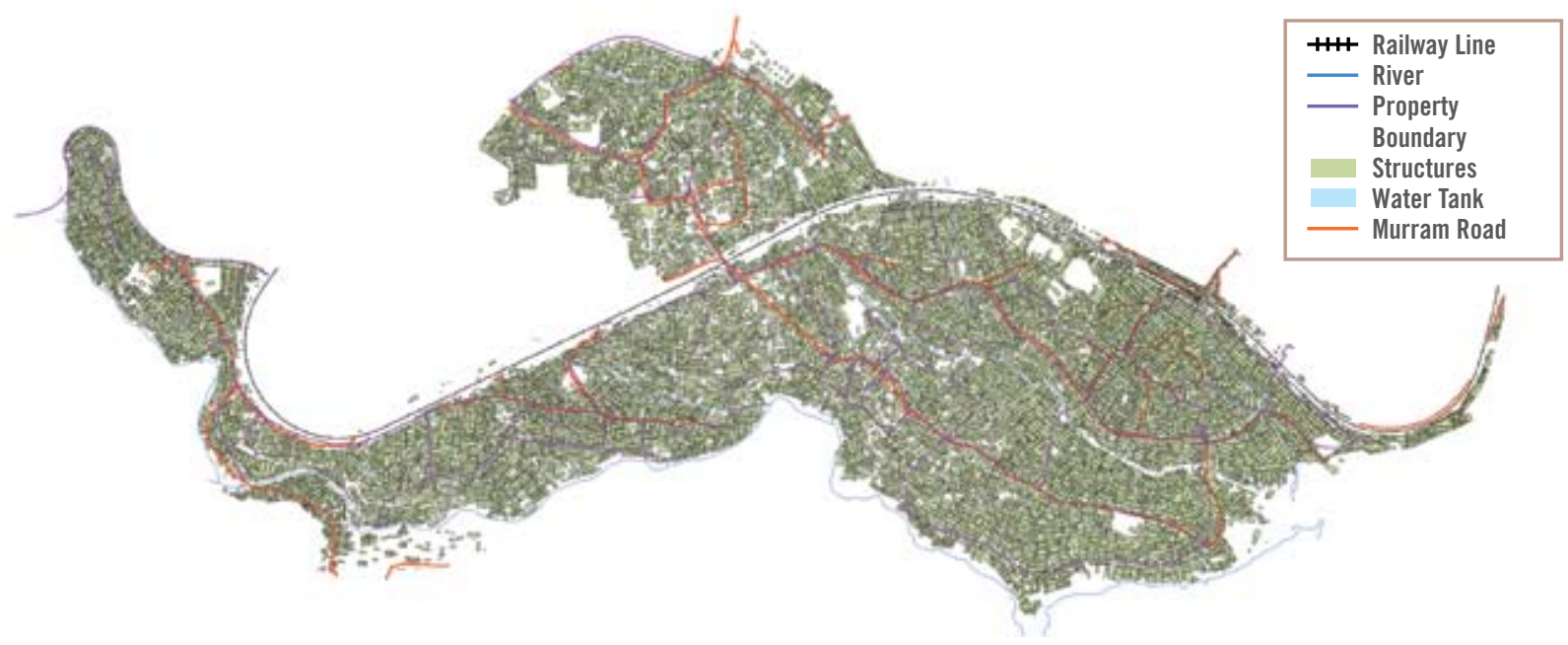

not widely available, and are often outdated; new structures are erected quickly as old ones are taken down, and what was yesterday a bakery might today be an electronics shop and tomorrow a hair salon. Informal channels of incorrect information and secrecy are also key contributors to conflicts.

Luckily, it is also information that is becoming easier and easier to develop and share via new technologies, allowing people to bypass traditional mechanisms and represent themselves. To help enable such representation, last October, my partner Mikel Maron and I began a project called Map Kibera with the objective of training residents to create their own map: the first online, public map of Kibera. We used tools from OpenStreetMap and partnered with local organizations such as the Social Development Network (SODNET), Carolina for Kibera, and Kibera Community Development Agenda (KCODA). This effort was a first step toward local ownership and creation of shared information.

Map-making has long been a means for exerting power; the Survey of Kenya still requires a justification for requesting some regional paper maps. Traditionally, maps have been essential military tools for conquering new lands. Without access to a map there is no way to plan for development and resource flows; it is easy for the powerful to overlook or extract from a region. In Kibera, for instance, water lines traverse the area bringing water to outlying areas while allowing for few inlets into Kibera itself, forcing residents to pay exorbitantly for a resource flowing right under their homes. ${ }^{2}$ Control of information, now more than ages of 19 and 34-one hailing from each village of Kibera, with a mix of young men and women and a variety of tribal affiliations. Realizing that the data collected would to make an impact, we also trained local community media members and others on digital tools such as Wordpress software and storytelling using Flip camcorders, enabling a rich assortment of tools for self-representation and storytelling to become available to the community.

Within three weeks, the mapping team had produced one of the densest maps ever made, labeling "points of interest" throughout Kibera. The mappers were allowed to choose what features were most important to collect, and agreed to try for every single water point, toilet, clinic, pharmacy, school, church, mosque, and NGO office, plus anything else at their discretion. They painstakingly uploaded the data using the Java OpenStreetMap editing software, overcoming a substantial lack of computer experience. Some signed up for their first email account. And all learned the joys of Facebook.

The map is available now through OpenStreetMap (OSM), a volunteer global mapping project often referred to as The Wikipeda of Maps. Based on the premise that crowdsourced information is more current and reliable than traditional means of collecting information, OSM allows anyone to contribute geographic details they have collected with GPS devices and other tools and add them to the map. Other data collection methods include tracing over aerial imagery, and drawing on and scanning paper maps, known as Walking 
Papers. A thriving global grassroots mapping community provides ever-increasing detail and coverage, monitors accuracy collectively, lobbies governments for data, and finds new ways to use geographic data. Recently, OSM volunteers mapped Haiti remotely to support emergency efforts. ${ }^{3}$

After the initial success of Map Kibera, we began to turn our attention to issues of sustainability and impact. We recently established a company called GroundTruth Initiative in order to expand work on mapping and digital citizen media to other regions, using Map Kibera as a pilot. The second phase expands on an evolving concept for GroundTruth: community information development-gathering, reporting, and analyzing local information using digital tools, and using that information for advocacy. The Map Kibera group is now working with local organizations to create a seamless link from the community to government agencies and others in powerful positions to make these collective voices heard. With support from Unicef and partners SODNET and KCODA, the new phase involves three concurrent threads: more detailed mapping in thematic areas such as health and education; media development including an Ushahidi website called Voice of Kibera and video news reporting; and SMS monitoring of services and incidents. A series of community meetings using a paper printout of the map will kick off community discussions on topics such as health, security, education and water, allowing for local feedback.

The final outcome should be nothing less than a new model for participation in civic processes, and a new representation of Kibera based on the knowledge held by its residents.

Erica Hagen founded Map Kibera with partner Mikel Maron in October of 2009, and established GroundTruth Initiative, LLC in March 2010. She received a Master's of International Affairs from Columbia University in New York, where she focused on journalism and international development. She has worked in four countries on project evaluation and communications, and in the United States on refugee and immigrant issues. She holds a B.A. from Reed College in Religion.

Kaushal Jhalla contributed to this article.

\section{Links}

http://mapkibera.org

www.openstreetmap.org

http://kibera.ushahidi.com

www.kcoda.org

www.sodnet.org

http://cfk.unc.edu

\section{References}

Kenya: The Unseen Majority: Nairobi's Two Million Slum-Dwellers, Amnesty International. London: Amnesty International Publications, 2009.

Notes

1 On the low end, see Stefano Marras, "Mapping the Unmapped," http://www.afronline.org/wp-content/uploads/2009/06/

kibera_mapping_the_unmapped.pdf

On the high end, see Amnesty International and many other NGOs: http://www.amnestyusa.org/all-countries/kenya/page.do?id=1011181

2 The Unseen Majority, p.6

3 Haiti Wiki: http://wiki.openstreetmap.org/wiki/WikiProject_Haiti
DESIGN THINKING

continued from page 31

design thinking in an organization. Perhaps the approach isn't embraced by the entire organization. Or maybe the organization resists taking a human-centered approach and fails to balance the perspectives of users, technology, and organizations.

One of the biggest impediments to adopting design thinking is simply fear of failure. The notion that there is nothing wrong with experimentation or failure, as long as they happen early and act as a source of learning, can be difficult to accept. But a vibrant design thinking culture will encourage prototyping-quick, cheap, and dirty-as part of the creative process and not just as a way of validating finished ideas.

Design thinking can lead to hundreds of ideas and, ultimately, real-world solutions that create better outcomes for organizations and the people they serve.

Tim Brown is the CEO and president of IDEO, a global innovation and design firm. He is author of Change by Design: How Design Thinking Transforms Organizations and Inspires Innovation (HarperBusiness, 2009), a newly published book about how design thinking transforms organizations and inspires innovation.

Jocelyn Wyatt leads IDEO's Social Innovation group, which works with enterprises, foundations, nongovernmental organizations, and multinationals to build capabilities in design thinking and design innovative offerings that meet the needs of local customers.

Adapted from the original article by Tim Brown and Jocelyn Wyatt, "Design Thinking for Social Innovation," Stanford Social Innovation Review (Winter 2010) vol.8, No. 1, pp.30-35.

\section{Notes}

1 Jocelyn Wyatt, E-mail correspondence with Kara Pecknold, September 23, 2009.

2 Tom Kelley and Jonathan Littman, The Ten Faces of Innovation: IDEO's Strategies for Defeating the Devil's Advocate and Driving Creativity Throughout Your Organization, New York: Random House, 2005.

3 “Accelerating Innovation for Development: The Rockefeller Foundation and Inno-Centive Renew Partnership Linking Nonprofit Organizations to World-Class Scientific Thinkers," Rockefeller Foundation, June 23, 2009.

\section{References}

7 Brown, Tim. Change by Design: How Design Thinking Transforms Organizations and Inspires Innovation, New York: HarperBusiness, 2009.

Minkel, J.R. "Net Benefits: Bed Netting, Drugs Stem Malaria Deaths: Proactive African Countries See Fewer Children Felled by the Mosquito-Borne Disease," Scientific American, February 4, 2008.

Pauling, Linus, Barclay Kamb, Linda Pauling Kamb, et al., Linus Pauling: Selected Scientific Papers, Volume II-Biomolecular Sciences, London: World Scientific Publishing, 2001.

Positive Deviance Initiative. "In Memoriam: Jerry Sternin,"

Positive Deviance Initiative. "Nutrition in Viet Nam,"

Positive Deviance Initiative. "The Viet Nam Story: Narrated by Jerry Sternin,"

Positive Deviance Initiative. "What Is Positive Deviance?"

Starr, Kevin. "Go Big or Go Home," Stanford Social Innovation Review, fall 2008. 